\title{
A cultura do Remix em publicações e republicações em CC BY, CC BY-SA e CC BY-NC.
} Éber Coelho Paraguassu (1)

\begin{abstract}
EDITORIAL
Resumo

As licenças Creative Commons foram idealizadas para permitir a padronização de declarações de vontade no tocante ao licenciamento e distribuição de conteúdos culturais em geral (textos, músicas, imagens, filmes e outros), de modo a facilitar seu compartilhamento e recombinação, sob a égide de uma filosofia copyleft. As licenças criadas pela organização permitem que detentores de copyright (isto é, autores de conteúdos ou detentores de direitos sobre estes) possam abdicar em favor do público de alguns dos seus direitos inerentes às suas criações, ainda que retenham outros desses direitos. Isso pode ser operacionalizado por meio de um sortimento de módulos-padrão de licenças, que resultam em licenças prontas para serem agregadas aos conteúdos que se deseje licenciar. Os módulos oferecidos podem resultar em licenças que vão desde uma abdicação quase total, pelo licenciante, dos seus direitos patrimoniais, até opções mais restritivas, que vedam a possibilidade de criação de obras derivadas ou o uso comercial dos materiais licenciados.
\end{abstract}

Palavras-chaves: CC BY, CC BY-SA, CC BY-NC, Creative Commons. 


\section{The culture of Remix in publications and republishings in $C C B Y, C C$ $B Y-S A$ and CC BY-NC.}

Creative Commons licenses were designed to allow the standardization of declarations of will regarding the licensing and distribution of cultural content in general (texts, music, images, films and others), in order to facilitate their sharing and recombination, under the aegis of a copyleft philosophy. The licenses created by the organization allow copyright holders (that is, content authors or rights holders over them) to abdicate to the public some of their rights inherent in their creations, even if they retain others of those rights. This can be made operational through an assortment of standard license modules, which result in licenses ready to be added to the content you want to license. The modules offered may result in licenses ranging from an almost total abdication by the licensor of his property rights, to more restrictive options, which prohibit the possibility of creating derivative works or the commercial use of the licensed materials.

Keywords: CC BY, CC BY-SA, CC BY-NC, Creative Commons.

Instituição afiliada: 1- Departamento de Implantodontia e Cirurgia Oral do GOE/UNIVAN.

Dados da publicação: Artigo recebido em 01 de Setembro, revisado em 10 de Setembro, aceito para publicação em 20 de Setembro e publicado em 30 de Setembro.

DOI: https://doi.org/10.36557/2674-8169.2020v2n10p01-05

Éber Coelho Paraguassu paraguassutans@gmail.com 


\section{Creative Commons e a cultura do Remix.}

As licenças e instrumentos de direito de autor e de direitos conexos da Creative Commons forjam um equilíbrio no seio do ambiente tradicional "todos os direitos reservados" criado pelas legislações de direito de autor e de direitos conexos. Os instrumentos fornecem a todos, desde criadores individuais até grandes empresas, uma forma padronizada de atribuir autorizações de direito de autor e de direitos conexos aos seus trabalhos criativos. Em conjunto, estes instrumentos e os seus utilizadores formam um corpo vasto e em crescimento de bens comuns digitais, um repositório de conteúdos que podem ser copiados, distribuídos, editados, remixados e utilizados para criar outros trabalhos, sempre dentro dos limites da legislação de direito de autor e de direitos conexos.

\section{Design e fundamentação das licenças}

Todas as licenças Creative Commons têm em comum muitas características importantes. Todas as licenças ajudam os criadores - a quem são chamados de licenciantes, quando utilizam os instrumentos - a manter o seu direito de autor e os seus direitos conexos, ao mesmo tempo que permitem que outras pessoas copiem, distribuam e façam alguns usos do seu trabalho - pelo menos, para fins não comerciais. Todas as licenças Creative Commons são aplicáveis em todo o mundo e duram o mesmo prazo que o direito de autor e/ou os direitos conexos aplicáveis (porque têm por base o direito de autor e/ou os direitos conexos). Estas características comuns constituem a forma de base. Os licenciantes podem depois optar por acrescentar autorizações adicionais, quando decidem de que forma pretendem que o seu trabalho possa vir a ser usado.

Um licenciante Creative Commons, responde a algumas perguntas simples para escolher a licença - primeiro, quero permitir o uso comercial ou não, e segundo, quero permitir trabalhos derivados ou não? Se o licenciante optar por permitir trabalhos derivados, pode exigir que todos aqueles que usam o seu trabalho - a quem são chamados de licenciados - disponibilizem o novo trabalho ao abrigo dos mesmos termos da licença. Esta ideia é Designada de "Compartilhalgual" e este (se for escolhido) é um dos mecanismos que ajuda o conjunto de bens comuns digitais a crescer ao longo do tempo. A Compartilhalgual foi inspirada pela GNU General Public License, usada por muitos projectos de software livre e código aberto.

\section{As Licenças}

\section{Atribuição CC BY}


Esta licença permite que outros distribuam, remixem, adaptem e criem a partir do seu trabalho, mesmo para fins comerciais, desde que Ihe atribuam o devido crédito pela criação original. É a licença mais flexível de todas as licenças disponíveis. É recomendada para maximizar a disseminação e uso dos materiais licenciados.

Imagem 1

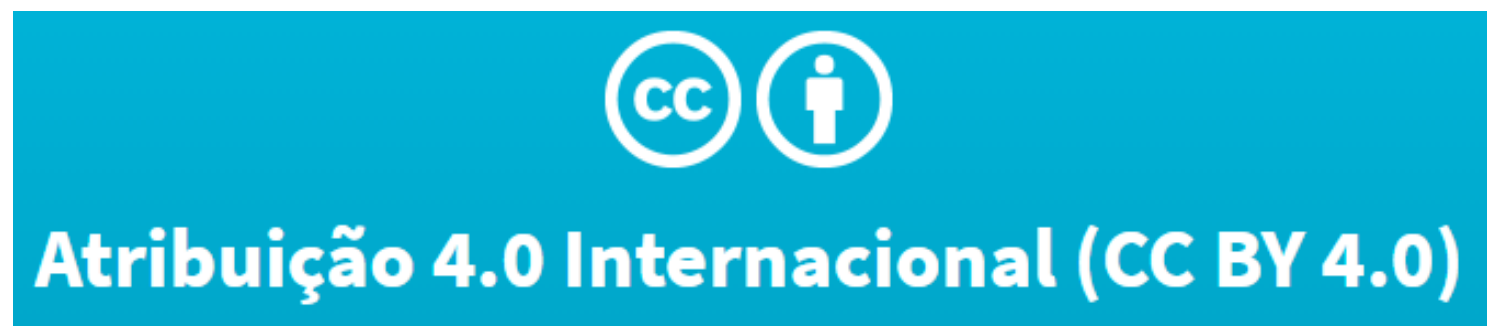

Imagem referente a atribuição CC BY

\section{Atribuição-Compartilhalgual CC BY-AS}

Esta licença permite que outros remixem, adaptem e criem a partir do seu trabalho, mesmo para fins comerciais, desde que lhe atribuam o devido crédito e que licenciem as novas criações sob termos idênticos. Esta licença costuma ser comparada com as licenças de software livre e de código aberto "copyleft". Todos os trabalhos novos baseados no seu terão a mesma licença, portanto quaisquer trabalhos derivados também permitirão o uso comercial. Esta é a licença usada pela Wikipédia e é recomendada para materiais que seriam beneficiados com a incorporação de conteúdos da Wikipédia e de outros projetos com licenciamento semelhante.

Imagem 2

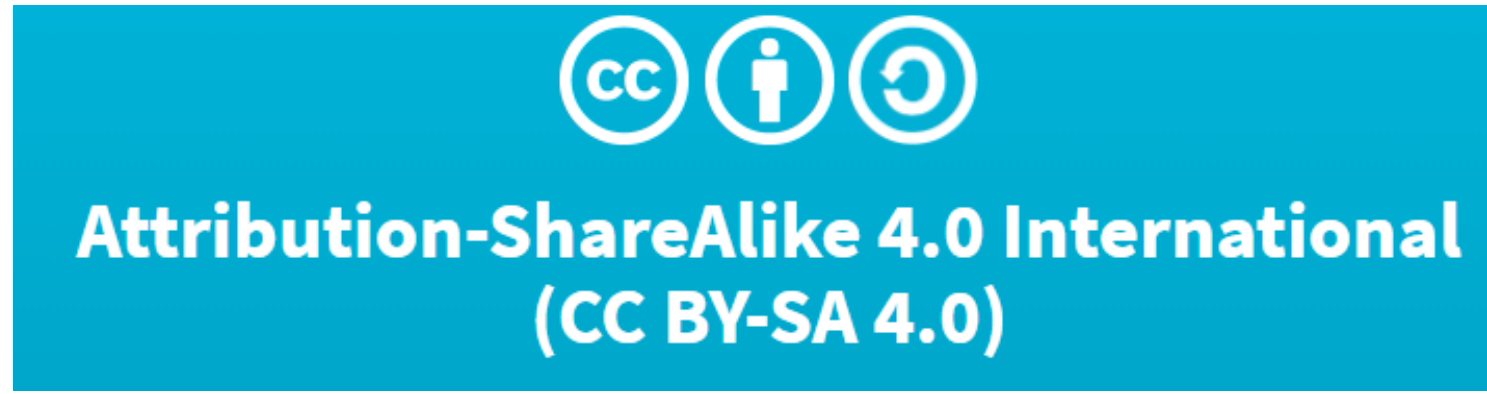

Imagem referente a atribuição Compartilhalgual CC BY-AS

\section{Atribuição-NãoComercial CC BY-NC}

Esta licença permite que outros remixem, adaptem e criem a partir do seu trabalho para fins não comerciais, e embora os novos trabalhos tenham de lhe atribuir o devido crédito 
e não possam ser usados para fins comerciais, os usuários não têm de licenciar esses trabalhos derivados sob os mesmos termos.

Imagem 3

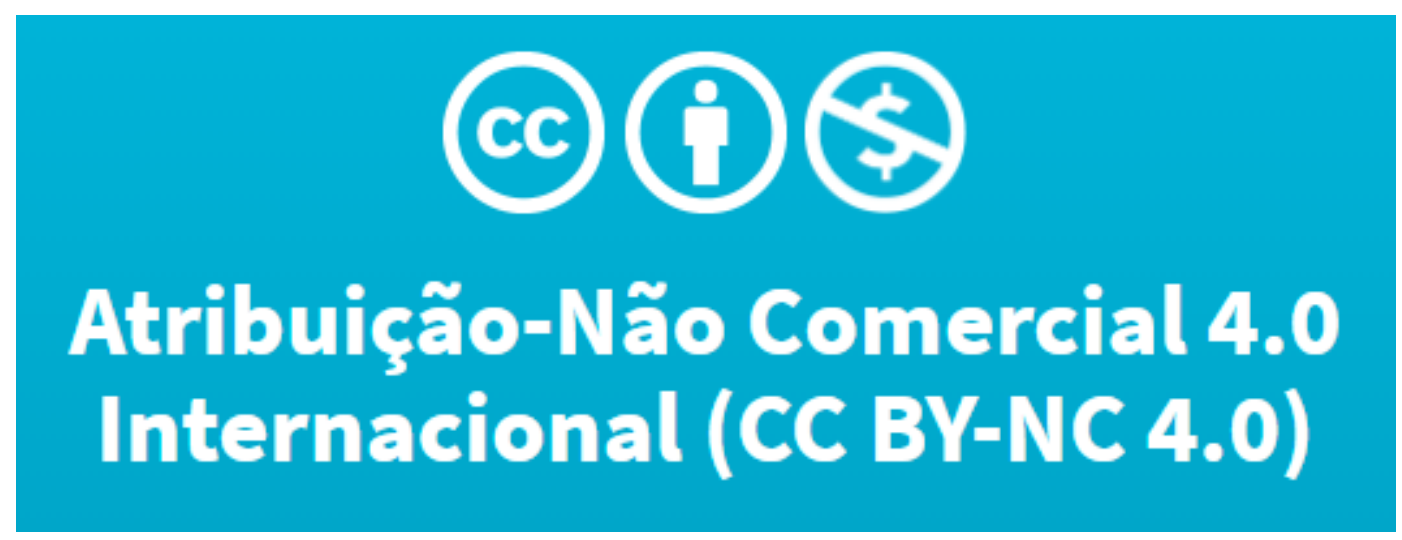

Imagem referente a atribuição NãoComercial CC BY-NC

\section{REFERÊNCIAS}

1 - Creative Commons. Disponível em https://br.creativecommons.org/licencas/

2- Wikipédia. Disponível em https://pt.wikipedia.org/wiki/Creative_Commons 